\title{
Karadeniz Bölgesindeki Devlet Hastanelerinin Sağlık Hizmetleri Etkinliğinin Analizi: 2018 Yılı İçin Veri Zarflama Analizinden Bulgular
}

\author{
Analysis of Health Care Effectiveness of State Hospitals in the Black Sea Region: Findings from Data
} Envelopment Analysis for 2018

\author{
Ufuk YAZICI ${ }^{1}$, Yıldırım Beyazıt ÇİÇEN ${ }^{2}$
}

\section{ÖZ}

Sağlık hizmeti, yüksek teknoloji barındıran ve insan kaynağının yoğun olduğu alanların başında gelmektedir. Topluma sağlik hizmeti sunumunda hastanelerin rolü birincil önemdedir. $\mathrm{Bu}$ noktada kaynaklarının etkin kullanımı ve etkin olmayan hastanelerin belirlenerek sağlık sektörüne ayrilan kaynak israfını ortadan kaldırmaya yönelik çalışmaların takibi ve önlemlerin alınması birey ve toplum sağlığı açısından son derece önemlidir.

$\mathrm{Bu}$ çalışmada, Karadeniz Bölgesi'nde hizmet veren devlet hastanelerinin etkinlik analizleri Veri Zarflama Analizi yöntemiyle gerçekleştirilmiştir. İlgili bölgede 124 adet hastane bulunmaktadır. Yapılan analizde kullanılmak üzere 5 adet girdi ve 6 adet çıktıdan faydalanılmıştır. Elde edilen bulgulara göre analize tabi tutulan 124 adet hastaneden 72 hastanenin etkin olduğu ancak 52 hastanenin ise etkin olmadığ tespit edilmiştir.

Anahtar Kelimeler: Etkinlik, Devlet Hastaneleri, Sağlık hizmeti, Veri zarflama analizi.

\begin{abstract}
Health care is one of the areas where high technology and human resources are intensive. The role of hospitals in providing health services to the community is of primary importance. The role of hospitals is of primary importance in providing healthcare services to the community. At this point, the effective use of hospital resources, the determination of inefficient hospitals and the monitoring of the waste of resources and taking measures are extremely important in terms of individual and public health.

In this study, effectiveness analyzes of state hospitals in the Black Sea Region were carried out with the Data Envelopment Analysis method. There are 124 hospitals in the relevant region. 5 inputs and 6 outputs were used for the analysis. According to the findings obtained, 72 hospitals were effective, but 52 hospitals were not.
\end{abstract}

Keywords: Effectiveness, State Hospitals, Healthcare, Data envelopment analysis.

Bu makale Gümüshane Üniversitesi, Sosyal Bilimler Enstitüsü, İktisat Yüksek Lisans Programı öğrencilerinden Ufuk Yazıcı’nın Dr. Öğretim Üyesi Yıldırım Beyazıt Çiçen danışmanlığında yaptı̆̆ "Karadeniz Bölgesinde Yer Alan Devlet Hastanelerinin 2018 Yılı Să̆lık Hizmetleri Etkinliğinin Veri Zarflama Analizi Yöntemi ile Değerlendirilmesi” adlı tezden türetilmiștir.

\footnotetext{
${ }^{1}$ Uzman, Ufuk YAZICI, Gümüşhane İl Sağl1k Müdürlüğü, ufukyazici0029@hotmail.com, ORCID: 0000-0002-0951-3801

${ }^{2}$ Dr. Öğretim Üyesi, Yıldırım Beyazıt ÇİÇEN, Gümüşhane Üniversitesi İiBF İktisat Bölümü, ybcicen@ gumushane.edu.tr, ORCID: 00000002-3425-280X 


\section{GíRiş}

"Sağllk" sözcüğü, canlı, diri kalma, sıhhatli olma anlamına gelir. Sözcügün köküne bakıldığında "Sağ" olduğu bilinmektedir. Günümüzde ise Dünya Sağlık Örgütü 1948 tarihli tüzüğünde sağlik kavramını "bireylerin hastalı veya sakatlığının olmayışı değil; bedenen, ruhen ve sosyal anlamda da tam bir iyilik hali" şeklinde tanımlamıştır. ${ }^{1}$

İnsan sağlığını doğrudan bozan faktörlerin ortadan kaldırılması, hastaların tedavilerinin sağlanması, bedeni ve ruhi kabiliyet ve melekeleri azalmış olanların işe alıştırılması, sağlığına tam kavuşamayanların rehabilite ederek temel ihtiyaçlarının karşılanması ve toplumun sağlik seviyesini geliştirme amacına yönelik tüm faaliyetlere sağlik hizmeti denilmektedir. ${ }^{2}$

Sağl1k sektörünün temel amac1, toplumun tüm fertlerinin sağlik hizmetinden yararlanmasını sağlamak, bireylerin sağlık seviyesini yükseltmek ve bunun için gerekli tüm imkân ve unsurlara ilişkin yapıların geliştirilmesidir. $\mathrm{Bu}$ amaçların etkin bir şekilde yerine getirilmesi için sağlık sistemlerinin performanslarının artırılması, sağlık personelinin doğru bir şekilde planlanması ve eğitilmesi, mevcut kaynakların daha verimli bir şekilde kullanılması, gelişen teknik ve teknolojilerin kullanılması, kalite standartlarının belirlenmesi ve denetleme mekanizmasının çalıştırılması gerekmektedir. Sağlık sektöründe kullanılan temel kaynaklar; sağlık hizmeti sunulması açısından gerekli finansal veya iktisadi kaynaklar ile sağlık personeli insan kaynağıdır. ${ }^{3}$

Sağlık kuruluşları, Türkiye'de sağlık hizmeti sunumunda önemli bir rol üstlenmiştir. Kaynakların etkin kullanılması adına sektörde etkinlik ölçümünün gerçekleştirilmesi ve buna bağlı olarak iyileştirici tedbirlerin alınması önem taşımaktadır. $\mathrm{Bu}$ tedbirler arasında sağlık kuruluşlarının profesyonel bir yönetim anlayışıyla yönetilmesi, kalite standartlarının yerine getirilmesi, denetim mekanizmasının etkin işletilmesi ve atıl kapasitelerin yeniden planlanarak tam kapasite hizmet verebilmesinin sağlanması sayılabilir.

Bu çalışmada Karadeniz Bölgesi'nde yer alan kamu hastanelerinin etkinliğinin ölçülmesi amaçlanmıştır. Literatürde bu bölge için yapılan hususi bir çalışma olmadığından, bu çalışmanın literatüre katkı sağlayacağı düşünülmektedir. $\mathrm{Bu}$ tarz etkinlik ölçümüne ilişkin çalışmaların farklı bölgeler ve farklı rollerdeki hastaneler için yapılması, hastanelerin daha iyi yönetilmesi açısından önem arz etmektedir.

Karadeniz Bölgesi'nde 18 şehir bulunmaktadır. Bölge kendi içinde Batı, Orta ve Doğu Karadeniz olarak ayrılmaktadır. 2019 itibariyle Karadeniz Bölgesi nüfusu 7 milyon 674 bin 496'dır. Bölgenin en büyük ve gelişmiş şehirleri Samsun, Trabzon ve Ordu'dur. Bölgenin yüz ölçümü 122 bin $121 \mathrm{~km}^{2}$ ile Türkiye topraklarının \%18'ini kapsamaktadir.

$\mathrm{Bu}$ çalışma beş bölümden oluşmaktadır. Giriş sonrası ikinci bölümde sağlık hizmetlerinin kavramsal çerçevesi açıklanmıştır. Bu başlıkta sağlık kavramı, sağlık kuruluşlarının basamakları ve rolleri açıklanmıştır. Devam eden üçüncü bölümde sağlık kurulunda etkinlik konusu ele alınmıştır. $\mathrm{Bu}$ başlıkta çalışmamızın uygulama aşamasında kullanılan Veri Zarflama Analizi (VZA) yönteminden ve Türkiye'de sağlık sektöründe yapılan etkinlik analizlerine ilişkin literatürden bahsedilmiştir. Dördüncü bölüm uygulama bölümüdür. $\mathrm{Bu}$ bölümde Karadeniz Bölgesi'nde yer alan kamu hastanelerinin belirli girdiler ve çıktılar baz alınarak etkinlik analizleri gerçekleştirilmiştir. Son bölüm sonuç ve değerlendirme bölümüdür. 


\section{SAĞLIK HİZETLERININ KAVRAMSAL ÇERÇEVESİ}

Sağlık hizmetleri üç aşamada sinıflandırılmaktadır: Koruyucu, tedavi ve rehabilite edici (iyileştirici) sağlı hizmetleri. Koruyucu sağlik hizmetleri, bireylerde hastalık bulguları oluşmadan önce alınan her türlü önlem hizmetini içermektedir. $\mathrm{Bu}$ önlemlerin en önemlileri arasında, aile planlaması, gıda denetimi, düzenli ve dengeli beslenme ile riskli grupların aşılanması sayılabilir. Koruyucu sağlık hizmetinden hem birey hem toplum fayda elde etmektedir. ${ }^{4}$

Bireyler koruyucu sağlık hizmeti aldıktan sonra da çeșitli nedenlerle hasta olabilmekte ve tedaviye ihtiyaç duyabilmektedirler. Tedavi edici sağlık hizmetleri; hasta olan, kaza geçiren ve çeşitli nedenlerle yaralanan bireylerin tanısının konulması, tedavisinin sağlanması için uygun hekimler ve teknolojik aletler ile sunulan sağlik hizmetidir. ${ }^{5}$ Rehabilite edici sağlık hizmetleri, tıbbi ve sosyal rehabilitasyon olmak üzere ayrıma tabi tutulur. $\mathrm{Bu}$ rehabilitasyon yardımıyla bireylerde ortaya çıkan kisitlılığın ortadan kaldırılması (organ yerine protez takılması, fizik tedavi hizmetinin sağlanması vb.), uygun işe yerleştirilmeleri veya uygun bakımı almalarıyla tekrar topluma kazandırılmasına yönelik olarak verilen sağlık hizmetleridir. ${ }^{6}$

\section{Sağlık Kurumlarının Tanımlanması ve Sinıflandırılması}

Sağlık kurumları incelendiğinde; genel hastaneler, eğitim ve araştırma hastaneleri, sağlık ocakları, toplum sağlığı merkezleri, verem savaş hizmeti veren dispanserler ve eczaneler gibi birçok sağlık kurumunun olduğu görülmektedir. Burada analizimizde hastaneler üzerinde durulmaktadır.

Günümüzde hastaneleri tanımlarken farklı tanımlarla karşılaşılmaktadır. Hastaneler; sağlık sunumunun etkin ve kesintisiz olarak üretildiği, sağlık alanında eğitimlerin verildiği, kendine özgü özellikleri bulunan, kullanılan araç gereç yönünden pahalı özellikte olan ve profesyonel şekilde yönetim tarzına sahip sağlık kurumları şeklinde tanımlamıştır ${ }^{7}$. Dünya Sağlık Örgütü ise hastaneleri; "müşahede, teşhis, tedavi ve rehabilitasyon olmak üzere gruplandırarak sağlık hizmetleri veren, hastaların uzun veya kısa süreli tedavi gördükleri yataklı kuruluşlar" şeklinde tanımlamıştır. ${ }^{8}$

\section{Türkiye'de Yer Alan Hastanelerin Sınıflandırılması}

Sağlık Bakanlığı'na bağlı tüm hastaneler, bireylere sağlık hizmeti sunan karmaşık yapıda kurumlar olmasından dolayı farklı şekilde sınıflandırılmışlardır. Bu kapsamda hastaneleri; mülkiyeti, büyüklükleri, verilen hizmet türü, hasta yatış süresi, eğitim statüsü, hizmet basamağı ve akreditasyon standartlarına göre sinıflandırmak mümkündür. ${ }^{9}$

Mülkiyetine göre hastaneler, hangi kurum bünyesinde hizmet verdiği ve özelliklerine göre belirlenirler. Ülkemizde mülkiyetine göre yapılan sınıflandırmada; Sağlık Bakanlığı'na, Üniversitelere, belediye ve özel kesime ait hastaneler şeklinde ayrım yapilmaktadir. $^{10}$

Büyüklüklerine göre hastanelere bakıldığında, büyüklüğün ölçülmesi için yatak sayısı ve personel sayısı gibi çeşitli veriler kullanılmaktadır. Yatak sayısı veri sınıflandırmasında sik kullanılmaktadır. Hastaneler genel anlamda 25 yataktan başlayarak 800 üstü yatak kapasitesiyle hizmet vermekte ve yatak sayılarına göre sinıflandırılmaktadırlar. ${ }^{11}$

Hizmet verdikleri türe göre hastaneler ise ikiye ayrılmaktadır. Bunlar genel ve dal hastaneleri şeklindedir. Genel hastaneler acil servis dahil olmak üzere tüm hastaların kabul edildiği hastanelerdir. Dal hastanelerinde ise belirli bir uzmanlık alanında hizmet verilmektedir. $\mathrm{Bu}$ hastanelerin büyüklükleri (yatak sayıları, personel sayıları) bölgenin nüfus yoğunluğuna göre değişmektedir. ${ }^{12}$

Hasta yatıș sürelerine göre hastaneler incelendiğinde, hastaneler ikiye ayrılmaktadırlar. Bunlar kısa ve uzun süreli kalınan hastanelerdir. Hastaların \%50'sinin 30 günden az tedavisinin yapıldığ kısa süreli kalınan hastanelerdir. Hastaların $\% 50$ 'sinin 30 günden fazla tedavisinin 
yapıldığı hastaneler ise uzun süreli hastane olarak tanımlanmaktadır. ${ }^{13}$

Hizmet basamaklarına göre hastaneler; birinci, ikinci ve üçüncü basamak hastaneler olarak sinıflandirılır. Burada sinıflandırma ayrımı tedavi verilen hastalıkların basitliğinden kompleksliğine yöneliktir. ${ }^{14}$

Sağllkta akreditasyona göre hastaneler standardizasyon üzerinden sinıflandirılmaktadır. Hastanelerde hastalara verilen hizmetler, belirlenmiş faktörlere göre ölçülmektedir. Örneğin dünyanın bilinen en eski akreditasyon kurumlarından Joint Commision International (JCI) sağlik kuruluşlarını akredite etmektedir. Benzer şekilde uluslararası standartlar organizasyonu belgesi sağlayan önemli bir diğer kuruluş ISO'dur (International Standardisation Organisation). Bu kuruluşlardan sağlanan akreditasyon belgesi ilgili hastanenin uluslararası standartlarda hizmet verdiğini göstermektedir. Ülkemizde de hastaneler toplam kalite yönetimi çerçevesinde ISO belgelerine sahip olma isteği içerisindedirler. ${ }^{15}$ Küreselleşmeyle birlikte hastalar sınır ötesi sağlık hizmeti alma arayışını artırmışlardır. $\mathrm{Bu}$ akreditasyon belgesini alan hastaneler medikal turizmden pay alabilme imkânına sahip olmaktadır. ${ }^{16}$

\section{Türkiye'de Yer Alan Hastanelerin Rolleri}

Sağlık Bakanlığı kaynakların etkin kullanımı, insan gücü tıbbi ve teknolojik donanım, bina tahsisinin doğru tespit edilmesi ve atıl kapasite yaratmamak adına hastanelere kriterlere dayalı belli roller vermektedir. $\mathrm{Bu}$ rol ve kriterler Tedavi Hizmetleri Genel Müdürlügü’nün 2009 tarih ve 46143 sayılı oluru ile aşağıdaki şekilde siralanmaktadır.

- A1 Grubu Genel Hastaneler: En az beş branşta eğitim yetkisi verilen ve bu yetkiye istinaden eğitim kadroları oluşturulmuş, üçüncü basamak tedavi ve rehabilitasyon hizmetlerinin verildiği, eğitim-araştırma faaliyetlerinin yürütüldüğü ve beraberinde uzman ve yan dal uzman tabiplerinin yetiştirildiği genel dal yataklı tedavi kurumlarıdır.
- A1 Grubu Dal Hastaneler: Eğitim ve araştırma hastanesi olarak hizmet veren dal hastaneleridir.

- A2 Grubu Genel Hastaneleri: Bölge sağlik merkezindeki illerde veya bu merkezlere bağlı diğer illerde faaliyet gösteren, eğitim-araştırma statüsü bulunmayan hastanelerdir.

- A2 Grubu Dal Hastaneleri: Eğitim ve araştırma hastanesi statüsünde olmayan tüm dal hastaneleridir.

- B Grubu Hastaneler: A1 ve A2 grubu hastaneleri dışında yer alan, il merkezlerindeki genel hastaneler ve güçlendirilmiş ilçelerde faaliyet gösteren hastanelerdir.

- C Grubu Hastaneler: Genel olarak güçlendirilmiş ilçe merkezlerinde kurulan sağlık kurumlarıdır.

- D Grubu Hastaneler: Güçlendirilmiş ilçelerle irtibatlandırılmış ilçelerde faaliyet gösteren en az 25 hasta yatağ 1 bulunan genel hastanelerdir.

- E Grubu Hastaneler: Hasta yatağ sayısı 25 yatağın altında olan entegre ilçe hastaneleridir. $\mathrm{Bu}$ hastane grubu kendi içinde E1, E2 ve E3 grubu hastaneler olarak 3'e ayrilmaktadir.

○ E1 Grubu Hastaneler: Toplam nüfusu 18 bin ve üzeri olan ilçelerde hizmet vermektedir.

- E2 Grubu Hastaneler: Toplam nüfusu 9 bin ve 18 bin aras1 yerleşim yerlerinde sağlık hizmeti sunmaktadırlar.

- E3 Grubu Hastaneler: Toplam nüfusu 9 bin altında olan yerleşim yerlerinde hizmet veren sağlık kuruluşlarıdır.

Türkiye'de yer alan hastanelerin rolleri, sayıları ve yatak sayıları Tablo 1'de verilmiştir. Tabloya göre, ülkemizde 819 hastanenin olduğu ve bu hastanelerin yaklaşı 145 bin yatak kapasitesiyle hizmet verdiği görülmektedir. E rolündeki hastane sayısının en fazla olduğu ancak yatak sayısı 
bakımından ilk sırayı A rolündeki hastanelerin aldığı görülmektedir.

Tablo 1. Türkiye'de Hastane Rollerine Göre Dağılımı (2019)

\begin{tabular}{|cccc|}
\hline No & Hastane Rolü & $\begin{array}{c}\text { Kurum } \\
\text { Sayısı }\end{array}$ & $\begin{array}{c}\text { Yatak } \\
\text { Sayısı }\end{array}$ \\
\hline $\mathbf{1}$ & A1 & 36 & 22346 \\
\hline $\mathbf{2}$ & $\begin{array}{c}\text { A1 Dal } \\
\text { Hastanesi }\end{array}$ & 29 & 11266 \\
\hline $\mathbf{3}$ & A2 & 60 & 29302 \\
\hline $\mathbf{4}$ & $\begin{array}{c}\text { A2 Dal } \\
\text { Hastanesi }\end{array}$ & 77 & 14971 \\
\hline $\mathbf{5}$ & B & 127 & 25625 \\
\hline $\mathbf{6}$ & C & 140 & 9843 \\
\hline $\mathbf{7}$ & D & 124 & 4925 \\
\hline $\mathbf{8}$ & E1 & 83 & 1981 \\
\hline $\mathbf{9}$ & E2 & 96 & 1467 \\
\hline $\mathbf{1 0}$ & E3 & 47 & 476 \\
\hline
\end{tabular}

Kaynak: Sağlık Bakanlığı İstatistik, Analiz ve Raporlama Daire Başkanlı̆̆ 1

Sağlık Bakanlığı son yıllarda sağlik hizmet bölgesi konumunda bulunan il merkezlerine şehir hastaneleri kurmaktadır.
Yapılan planlamalar çerçevesinde şehir hastaneleri kampüsünün içinde; genel hastaneler, onkoloji hastaneleri, kalp ve damar hastanesi, kadın doğum hastanesi başta olmak üzere sağlik tesisleri bulunmaktadır. Bu sağlık tesisleri kamu-özel ortaklığ geçirilmektedir. ${ }^{17}$ Ancak şehir hastaneleri yukarıda verilen hastane rolleri içerisinde yer almamaktadır. Şehir hastaneleri hem bu roller sınıfında yer almadı̆̆ından hem de halihazırda yapımı devam eden şehir hastaneleri olduğundan analize dahil edilmemiştir. $\mathrm{Bu}$ tarz büyük hastanelerinin analizinin ayrı bir çalışmada yapılması daha uygun görülmektedir. Bu çalışmada kamu hastaneleri analize tabi tutulmuştur. Karadeniz Bölgesi'nde Samsun, Ordu, Trabzon ve Rize illerinde şehir hastaneleri yapım aşamasındadır.

\section{LİTERATÜR}

Sağlık hizmetinin kendine has özelliklerinden dolayı girdi ve çıktı değişken sayısı oldukça yüksektir. $\mathrm{Bu}$ değişkenleri kendi aralarında kıyaslamak, etkinliği yüksek olanı belirlemek ve etkin olmayanları etkin hale getirmek için kurumlar parametrik olmayan yöntemlerden VZA yöntemini kullanmaya başlamışlardır. VZA yöntemi ile çok sayıda sektörde verimlilik ve etkinlik analizi yapılmıştır.

$\mathrm{Bu}$ bölümde literatürde VZA'dan yararlanarak Türkiye'de sağlık alanında yapılan güncel analizlere kronolojik olarak yer verilmiştir. Literatür araştırmasında özellikle geniş çaplı il ve bölge analizleri dikkate alınmıştır. Detaylı literatür yüksek lisans tezinde yer almaktadır.

Şahin $(2008)^{18}$ çalışmasında 2003 yılını dikkate alarak 352 Sağlık Bakanlığ hastanesini incelemiştir. Çalışmada girdi olarak doktor sayıs1, mevcut yatak sayıs1, hemşire sayısı, hizmet üretim giderleri ve diğer personel sayısı kullanılmıştır. Çıktı olarak ise ayaktan hasta sayısı, yatan hasta sayısı ve ameliyat sayısı kullanılmıştır. Bulgu olarak incelenen hastanelerin \%22'si etkin bulunmuştur.

Öztürk (2009) ${ }^{19} \quad$ çalışmasında 2008 y1lındaki üniversite hastanelerini analiz etmiştir. Çalışmada girdi olarak uzman hekim sayıs1, yatak sayıs1 ve pratisyen hekim sayıs1; çıtı olarak yatan hasta sayısı, yatılan gün sayıs1, ameliyat ve muayene gün sayıları kullanılmıştır. Elde edilen bulgulara göre 13 adet sağlık kuruluşu toplam etkin, 15 tanesinin ölçek etkin ve 18 tanesinin ise teknik etkindir.

Aytekin $\quad(2011)^{20}$ çalışmasında 2009 yılında yatak işgal oranı düşük 245 hastaneyi incelemiştir. Çalışmada girdi olarak uzman doktor sayıs1, yatak sayıs1, pratisyen hekim sayısı ve yardımc1 personel sayısı; çıktı olarak ise hastane ciroları, yatak işgal oranı, ortalama kalış gün süresi ve yatan hasta oranı kullanılmıştır. Hastanelerden sadece \%26'sının etkin olduğu saptanmıştır.

Bal ve Bilge $(2013)^{21}$ çalışmasında İstanbul, Ankara, İzmir, Bursa ve Adana ilinde yer alan 35 adet eğitim ve araştırma hastanesi incelemiştir. Dönem olarak 20072009 arası dikkate alınmıştır. Çalışmada girdi 
olarak yatak sayısı, asistan ve uzman doktor sayısı ve hemşire sayısı; çıktı olarak ise gelir, muayene sayıs1, yatılan gün ve ameliyat sayısı dikkate alınmıştır. Elde edilen bulgulara göre 13 hastanenin tam etkin olduğu, 22 hastanenin ise etkin olmadığ1 sonucuna ulaşılmıştır.

Demiray ve Güneş $(2014)^{22}$ çalışmasında Türkiye'deki 81 ilin sağl1k etkinliğini 20062011 dönemi için analiz etmiştir. Çalışmada girdi olarak hastanede çalışan uzman ve pratisyen hekim sayısı, yatak sayısı ve döner sermaye harcamaları; çıktı olarak ise poliklinikte tedavi olan hasta sayıs1, taburcu olan hasta sayısı, ölen hasta sayısı, büyük, orta ve küçük ameliyat sayısı ve döner sermaye gelirleri kullanılmıştır. Elde edilen bulguya göre 81 il içerisinde 46 ilin etkin olduğu bulunmuştur.

Öksüzkaya $\quad(2017)^{23} \quad$ çalışmasında Türkiye'de sağlık sektörünün 2013 yılına ait bölgesel etkinliğini incelemiştir. Çalışmada girdi olarak pratisyen ve uzman hekim sayis1, ebe ve hemşire sayısı ile yatak sayısı; çıktı olarak ise ameliyat say1s1 ve yatan hasta sayısı ele alınmıştır. Elde edilen bulgulara göre Akdeniz, Ege, Batı Anadolu, Güneydoğu Anadolu ve Kuzeydoğu Anadolu Bölgesi'nde yer alan sağlık kuruluşları etkin olarak bulunmuştur.

Şenol ve Gençtürk (2017) ${ }^{24}$ çalışmasında Türkiye'deki 80 ilde yer alan kamu hastaneleri birlikleri analiz etmiştir. Çalışmada girdi olarak yatak sayısı, hemşire ve ebe ile hekim sayısı; çıtı olarak ise acil muayene sayısı, poliklinik muayene sayıs1, $\mathrm{A}, \mathrm{B}$ ve $\mathrm{C}$ grubu ameliyat sayısı ile yatan hasta sayısı kullanılmıştır. Elde edilen bulgulara göre bu hastane birliklerinden \%25'i CCR tekniğine göre, \%38'i BCC tekniğine göre verimli bulunmuştur. Ayrıca verimliliği en yüksek illerin Güneydoğu Anadolu Bölgesi'nde bulunan iller olduğu görülmüştür.

Bağcı (2018) ${ }^{25}$ çalışmasında 2016 yılı için Sağlık Bakanlığg'na bağlı kamu hastanelerinin hizmet performansinı incelenmiştir. Çalışmada girdi olarak ilk madde ve malzeme gideri, genel yönetim gideri, personel gideri ve ücreti, tescilli yatak sayıs1, diğer hizmet maliyetleri, asistan sayıs1, pratisyen ve uzman hekim sayıs1, hemşire ve ebe sayısı ile diğer personel sayısı; çıktı olarak toplam yatan hasta sayısı, döner sermaye satış hasılatı, A, B ve C grubu ameliyat sayısı ve toplam ayaktan muayene sayısı alınmıştır. Elde edilen temel bulguya göre büyük kapasiteye sahip hastanelerin daha etkin olduğu, hastane rolleri azaldıkça etkinliğin düştüğü sonucuna ulaşılmıştır.

Çınaroğlu $(2018)^{26}$ çalışmasında 2014 yılında Sağlık Bakanlığı'na bağlı eğitim araştırma hastanesi olan ve olmayan sağlık kuruluşlarının etkinliğini araştırmıştır. Çalışmada girdi olarak pratisyen ve uzman doktor sayısı ile yatak sayısı; çıktı olarak ise hastanede kalış gün süresi, yatan hasta sayısı, muayene sayısı ve ameliyat sayıları dikkate alınmıştır. Elde edilen bulguya göre eğitim ve araştırma hastanelerinin etkinliğinin diğer hastanelere göre tam olduğu görülmüsstür.

Esen ve Yiğit (2019) ${ }^{27}$ çalışmasında 2018 yılı için Akdeniz Bölgesi'nde yer alan kamu hastanelerinin etkinliğini ölçmüştür. Çalışmada girdi olarak uzman doktor sayısı, yatak sayısı, gider düzeyi ve hemşire sayıları; çıktı olarak ise ameliyat sayısı, gelir düzeyi, yatak doluluk oranı ve muayene sayısı kullanılmıştır. Çalışmada CCR modeli sonucunda hastanelerin \%36,7'sinin etkin olduğunu sonucu bulunmuştur. Diğer bir bulguya göre hastanelerin verimlilik düzeyleri ile hizmet rol grupları arasındaki ilişki istatistiki olarak anlamlıdır.

Taşkaya $(2020)^{28} \quad$ çalışmasında 2017 yılında Türkiye'de sağlık hizmeti sunan 59 adet eğitim ve araştırma hastanelerinin verimliliği analiz etmiştir. Çalışmada girdi olarak doktor, hemşire ve yatak sayısı; çıktı olarak ise toplam başvuru yapan hasta sayısı, yatan hasta sayıs1, yatak devir hız1, yatak işgal oranı, ortalama yatış süresi ve ameliyat sayısı kullanılmıştır. Elde edilen temel bulguya göre hastanelerin üçte birinin etkin olmadığı görülmüştür. 


\section{MATERYAL VE METOT}

\section{Sağlık Kurumlarında Etkinlik}

Günümüzde kamu kaynaklarının etkin kullanılmaması kamu harcamalarının artmasına, bütçe açıklarına ve bunların sonucunda ülkeler için iktisadi problemlere sebep olabilmektedir. Kamu işletmelerinin etkinlik değerlendirilmesinde diğer sektörlerden farklı yanlar bulunmaktadır. Diğer işletmeler üretim sonucunda elde edilen ürünün satışı üzerinden verimlilik hesaplaması yaparken, kamu işletmelerinde ise; girdi-çıktı ilişkisinden oluşacak verimliliğin üzerinde durulmaktadır. ${ }^{29}$

Kamu sektörleri diğer işletmelerle kıyaslandığında etkinlik açısından başarısız olduğu görülmektedir. Kamu Tercihi Teorisi'nde ifade edildiği üzere kamuda çalışanların bireysel fayda maksimizasyonu peşinde olması, kamusal faydanın ihmal edilmesi, denetim ve ölçümde zorluklar, farklı çıkar gruplarının rant-arama faaliyetleri ve temsil sorunu kamu sektöründe etkinsizlik oluşturan bazı temel nedenlerdir. ${ }^{30}$

Sağlık hizmetinin temel amac1, bireylerin sağlık kalitesini yükselterek hastalıktan korunmasını sağlamaktır. $\mathrm{Bu}$ noktada toplumda bireylerin sağlı hizmetine erişebilir olması, alınan sağlık hizmetlerinin etkin olması ve kapsayıcılığının sağlanması politika yapıcılarının hassasiyet göstermesi gereken bir konudur. Günümüzde sağlık alanında sosyal, ekonomik ve teknolojik yönden oluşan gelişmeler sağlık sektörünü yüksek kaynakların harcandığı bir sektör haline getirmiştir. Artan maliyetler sonucunda özellikle sağlık kuruluşlarında kaynakların etkinliğinin artırılması adına yapılan çalışmalar son derece önemlidir. Ancak çoğu ülkedeki genel kamuoyu bu konuda bir çözüm arayışı içerisinde değildir. $^{31}$

Kaynakların yetersiz olması etkinlik kavramının önemini artırmaktadır. Etkinlik analizinde kullanılan birçok yöntem bulunmaktadır. Başlıcaları arasında; sağlık kuruluşlarının ve sistemlerinin göreli etkinliğini ölçmeyi amaçlayan analitik araçlar, analitik etkinlik ölçüm yöntemleri (parametrik veya parametrik olmayan yöntemler ve deterministik veya stokastik yaklaşımlar), düzeltilmiş olağan en küçük kareler, stokastik sinır analizi (fonksiyonun bilinmeyen parametrelerinin maksimum olabilirlik teknikleri ile tahmin edilmesi) sayılabilir. VZA diğer tüm üretim birimlerinin göreceli etkinlik ölçümlerini türetmek için doğrusal programlama yoluyla doğrusal bir etkinlik sınırı belirleyen parametrik olmayan bir yaklaşımdır. VZA non-parametrik bir teknik olarak sağlık kurumlarında siklıkla kullanılan bir yöntemdir. ${ }^{32}$

\section{Veri Zarflama Analizi}

VZA, Farrell (1957) "Üretken Verimlilik Ölçümü” (The Measurement of Productive Efficiency) ${ }^{33}$ çalışmasından esinlenilerek Charnes, Cooper ve Rhodes (1978) (CCR) tarafindan geliştirilmiştir. ${ }^{34} \mathrm{Bu}$ model sadece ölçeğe göre sabit getiriyi ele almıştır. VZA, ortaya çıktığı ilk dönemlerde kâr amacı olmayan kurumların verimliliğini ölçmede kullanılmıştır. Verimlilik çıktıların girdilere oranı olarak bilinmektedir. Verimlilik kavramı, etkinlik ile doğru orantılı bir kavram olarak kabul edilir ve organizasyonların faaliyetleri sonucunda hedeflerine ulaşmasının değerlendirilmesinde kullanılmaktadır. ${ }^{35}$ Etkinlik bir optimizasyon çözümü olarak da ifade edilmektedir. Diğer bir ifadeyle etkinlik, minimum girdi ile maksimum çıktı arayışıdır. ${ }^{36}$ VZA, daha sonraki dönemde geliştirilerek kâr amacı taşıyan kurumların performansını ve etkinliğini ölçmede kullanılan bir yöntem olmuştur. VZA'da diğer bir yöntem; Banker, Charnes ve Cooper (1984) modelidir (BCC). ${ }^{37} \mathrm{Bu}$ model ölçeğe göre sabit, artan ve azalan getirinin analizinin yapılması olanağı sağlanmıştır. Modelde teknik etkinlik, toplam etkinliğe oranlanarak ölçek etkinliğe ulaşılabilmektedir. ${ }^{38}$ BCC modeli, CCR modelindeki gibi girdiye ve çıktıya yönelik olarak yorumlanabilmektedir.

VZA'nın temel amaçlarından bir tanesi ne kadar girdi azaltılarak ne kadar çıktı artırımı 
yapabileceğimizi görmektir. Elde edilen bulgularla belirlenen girdi ve çıktıların etkinliğini artırmak mümkün hale gelmektedir.

Özetle VZA, birbirine benzer üretim aşamasına sahip organizasyonların etkinlik ve verimliliğini göreli olarak ölçmek için geliştirilmiş bir yöntemdir. Girdi ve çıktıların birden çok kullanılarak yapılabildiği VZA, benzer kurumların etkinsizlik miktarını ve sebep olan nedenlerini belirlemekte ve iyileştirme çalışmalarının yapılmasına yardımcı olmaktadır. Model bu özelliği neticesinde birçok hizmet sahasında yaygın olarak kullanılmaktadır. ${ }^{39}$

\section{Uygulamada Kullanılan Yöntem ve Veriler}

$\mathrm{Bu}$ çalışmada, Karadeniz Bölgesi'nde yer alan 18 ilin tüm kamu hastaneleri rollerine göre ayrılarak etkinliklerinin hesaplanması ve sunulacak sağlık hizmetinin daha etkin ve iyi duruma getirilmesi amaçlanmaktadır. $\mathrm{Bu}$ kapsamda 18 ilde yer alan kamu hastanelerinin 2018 y1lı verileri Sağlık Bakanlığı'nın Temel Sağlık İstatistikleri Modülü'nden (TSIM) temin edilmiştir. Gerekli düzenlemeler yapıldıktan sonra VZA yöntemi ile hastanelerin etkinlikleri hesaplanmıştır. $\quad \mathrm{Bu}$ yöntemin kullanılmasındaki en büyük neden, birçok girdi ve çıtının kullanılabilirliğinin kolay olmasıdır.

Hesaplama sonucunda etkin olmayan hastanelerin belirlenen girdi ve çıtılarında ne ölçüde azaltma veya artırma yapılması gerektiği ölçülmüştür. Ayrıca etkin olmayan hastanelerin, etkin hale dönüşmesi için hangi etkin hastaneleri referans alması gerektiği belirlenmiştir. Çalışmada yer alan hastaneler rollerine göre ayrı ayrı değerlendirilmiştir.

VZA hesaplanmasında birçok program kullanılmaktadır. $\mathrm{Bu}$ çalışmada ise Win4DEAP (Versiyon 2.1) programından yararlanılmıştır. VZA yönteminin ilk aşaması karar verme birimlerinin (KVB) belirlenmesidir. Çalışmalarda KVB'nin güvenilirliği son derece önemlidir. $\mathrm{Bu}$ nedenle araştırmaların ilk aşamasında dikkat edilmesi gereken konulardan biri, kullanılan verilerin değişkenler arasındaki ilişkileridir. $\mathrm{Bu}$ çalışmada KVB olarak Karadeniz Bölgesi'nde yer alan 18 ilde hizmet veren kamu hastaneleri belirlenmiştir. $\mathrm{Bu}$ hastanelerin etkinliğini hesaplamak için 5 girdi ve 6 çıktı değişkeni kullanılmasına karar verilmiştir.

$\mathrm{Bu}$ tür çalışmalarda KVB değişkenleri arasındaki oranı belirlemede genel olarak $(\mathrm{n}+\mathrm{c}+1)$ kuralı dikkate alınmaktadır. $\mathrm{Bu}$ kuralda $\mathrm{n}$ girdi ve $\mathrm{c}$ çıktı sayısıdır. $\mathrm{Bu}$ çalışma kapsamında $5+6+1=12$ değişken kullanılması gerekmektedir. Çalışma incelendiğinde Karadeniz Bölgesi'nde yer alan kamu hastaneleri sayısı rollere göre ayrıldığında A rolünde olan hastane sayısı 33 adet, B rolünde olan hastane sayısı 19, C rolündeki hastane sayısı $25, \mathrm{D}$ rolündeki hastane sayıs1 26, E rolündeki hastane sayısı ise 21 olduğu görülmektedir. E2-E3 rolündeki hastanelerin girdi ve çıtıları yetersiz olduğundan hesaplamaya dâhil edilmemiştir.

Tablo 2'de çalışmada kullanılan değişkenlere yer verilmiştir. Tabloda verilen girdi değişkenlerinden yatak sayısı ilgili hastaneye ait toplam yatak sayısın1, uzman hekim sayıs ilgili hastanede hizmet veren uzman hekim sayısını, pratisyen hekim sayısı ilgili hastanede hizmet veren pratisyen hekim sayısını, hemşire sayısı ilgili hastanede hizmet veren hemşire sayısın1, ebe sayıs1 ilgili hastanede hizmet veren ebe sayısinı göstermektedir. Çıktı değişkenlerinden poliklinik sayısı ilgili hastanede ait poliklinik oda sayısın1, yatan hasta sayıs1 ilgili hastanede 2018 yılında toplam yatan hasta sayısını, A grubu ameliyat sayısı ilgili hastanede yapılan özellikli ameliyat ve girişim sayısını, B grubu ameliyat sayısı ilgili hastanede yapılan özel ameliyat ve girişim sayısını, C grubu ameliyat sayısı ilgili hastanede yapılan büyük ameliyat ve girişim sayısını, günübirlik ameliyat sayısı yapılan küçük girişimsel ameliyat sayısını göstermektedir. E1 rolündeki hastanelerde A, $\mathrm{B}$ ve $\mathrm{C}$ grubu ameliyat yapılması riskli olmasından dolayı yapılan analizde bu tür roldeki hastanelerin çıktısı olarak günübirlik ameliyat sayıları temel alınmıştır. Çalışmada 
veri kümesinin oluşturulması için her hastaneye rol sirasiyla 1'den n'e kadar kodlar verilmiş ve hastane adları bu kodlar üzerinden açıklanmıştır.

Tablo 2. Çalış̧mada Kullanılan Girdi ve Çıktı Değişkenleri

\begin{tabular}{|c|c|}
\hline Kullanılan Girdiler & Kullanılan Çıktılar \\
\hline Yatak Sayısı & Poliklinik Sayısı \\
Uzman Hekim Sayısı & Yatan Hasta Sayısı \\
Pratisyen Hekim Sayısı & A Grubu Ameliyat Sayısı \\
Hemşire Sayısı & B Grubu Ameliyat Sayısı \\
Ebe Sayısı & C Grubu Ameliyat Sayısı \\
& Günü Birlik Ameliyat \\
& Sayısı \\
\hline
\end{tabular}

\section{Araștırma Modelinin Belirlenmesi}

Sağlık kuruluşlarının çıktı değişkeninden daha çok girdi değişkeni üzerinde kontrol etme gücü fazla olduğu için modelin girdi odaklı olmasına karar verilmiştir. Çıktı değişken odaklı modelin tercih edilmeme nedeni çıktıların dış etmenlere bağlı olması ve yönetimin kontrol gücünü tam anlamıyla sağlayamamasından kaynaklanmaktadır. ${ }^{40}$

$\mathrm{Bu}$ çalışmada, girdi değişken odaklı BCC modeli tercih edilmiş, hesaplamada toplam etkinlik (CRS) ve teknik etkinlik (VRS) değeri bulunmuş bu değerler birbirlerine oranlanarak ölçek etkinliğine (SCALE) ulaşılmıştır. Çıkan sonuçlar neticesinde etkin hastaneler bulunmuş, etkin olmayan hastanelerin girdi değişkenlerinin hangi miktara getirilmesi gerektiği bilgisi verilerek referans alması gereken hastaneler belirlenmiştir. Her hastane rollerine göre değerlendirilmiştir. Sadece A grubu hastanelerin bünyesinde branş hastaneleri olduğundan dolayı etkinlik hesaplamasının doğru sonuçlar verebilmesi için kendi aralarında ayrı başlıklarda değerlendirilmiştir. Ayrıca E2-E3 rolündeki hastanelerin girdi ve çıktı değişkenleri istenilen miktarda olmamasi nedeniyle etkinlik ölçümü gerçekleştirilememiştir.

\section{BULGULAR VE TARTIŞMA}

\section{A Grubu Hastanelerin Etkinlik Ölçümü}

Tablo 3'te A grubu kamu hastanelerinin etkinlik ölçümleri VZA yönteminden faydalanarak hesaplanmıştır.

Elde edilen bulgulara göre CRS hesaplanmasinda A1, A5, A21, A25 ve A27 kodlu hastanelerin tam etkin olmadığ hastanelerin ise etkin olduğu gözlenmektedir. CRS ortalama etkinlik sonucu ise 0.982 olarak hesaplanmış ve sadece A1 kodlu hastanenin ortalama üzerinde bir değer aldığ gözükmektedir.

Ayrica hastanelerin VRS hesaplanmasinda A1, A5, A21, A25 ve A27 kodlu hastanelerin etkin olmadığı gözlemlenmiş ve VRS ortalama etkinlik skoru 0.988 olarak hesaplanmıştır. $\mathrm{Bu}$ hesaplama sonucunda etkin olmayan tüm hastaneler ortalamanın altında kalmıştır.

Ölçek etkinliği hesaplamasında ise A1, A5 ve A27 kodlu hastanelerin etkin olmadığ görülmektedir. Ölçek etkinliği ortalama skoru ise 0.994 olarak hesaplanmıştır. A5 hastanesi ortalamanın üstündedir.
Tablo 3. A Grubu Hastanelerin Etkinlik Sonuçları

\begin{tabular}{|cccc|}
\hline $\begin{array}{c}\text { A Grubu } \\
\text { Hastaneler }\end{array}$ & $\begin{array}{c}\text { Toplam } \\
\text { Etkinlik } \\
\text { (CRS) }\end{array}$ & $\begin{array}{c}\text { Teknik } \\
\text { Etkinlik } \\
\text { (VRS) }\end{array}$ & $\begin{array}{c}\text { Ölçek } \\
\text { Etkinliği } \\
\text { (SCALE) }\end{array}$ \\
\hline A1 & 0,975 & 0,986 & 0,988 \\
\hline A2 & 1,000 & 1,000 & 1,000 \\
\hline A5 & 0,868 & 0,871 & 0,997 \\
\hline A6 & 1,000 & 1,000 & 1,000 \\
\hline A7 & 1,000 & 1,000 & 1,000 \\
\hline A8 & 1,000 & 1,000 & 1,000 \\
\hline A10 & 1,000 & 1,000 & 1,000 \\
\hline A12 & 1,000 & 1,000 & 1,000 \\
\hline A13 & 1,000 & 1,000 & 1,000 \\
\hline A14 & 1,000 & 1,000 & 1,000 \\
\hline A17 & 1,000 & 1,000 & 1,000 \\
\hline A19 & 1,000 & 1,000 & 1,000 \\
\hline A20 & 1,000 & 1,000 & 1,000 \\
\hline A21 & 0,923 & 0,923 & 1,000 \\
\hline A22 & 1,000 & 1,000 & 1,000 \\
\hline A25 & 0,983 & 0,983 & 1,000 \\
\hline A26 & 1,000 & 1,000 & 1,000 \\
\hline A27 & 0,883 & 0,987 & 0,895 \\
\hline A28 & 1,000 & 1,000 & 1,000 \\
\hline A31 & 1,000 & 1,000 & 1,000 \\
\hline A32 & 1,000 & 1,000 & 1,000 \\
\hline
\end{tabular}

Örnek olması açısından A grubunda etkin olmayan hastanelerin referans alması gereken hastaneler Tablo 4'te yer almaktadır. Diğer 
grup hastanelerin referans alması gereken hastanelere yapılan tezden ulaşılabilir.

Tablo 4. Etkin Olmayan A Grubu Hastanelerin Referans Alması Gereken Hastaneler

\begin{tabular}{|c|c|c|}
\hline $\begin{array}{c}\text { Etkin } \\
\text { Olmayan } \\
\text { Hastaneler }\end{array}$ & $\begin{array}{c}\text { Referans Alması } \\
\text { Gereken Hastaneler }\end{array}$ & $\begin{array}{c}\text { Referans } \\
\text { Sayısı }\end{array}$ \\
\hline $\mathrm{A} 1$ & $\begin{array}{c}\mathrm{A} 7, \mathrm{~A} 10, \mathrm{~A} 14, \mathrm{~A} 31, \\
\mathrm{~A} 32\end{array}$ & 5 \\
\hline A5 & $\mathrm{A} 6, \mathrm{~A} 8, \mathrm{~A} 19, \mathrm{~A} 32$ & 4 \\
\hline A21 & $\begin{array}{c}\mathrm{A} 2, \mathrm{~A} 7, \mathrm{~A} 10, \mathrm{~A} 12, \\
\mathrm{~A} 26\end{array}$ & 5 \\
\hline A 25 & $\begin{array}{c}\mathrm{A} 2, \mathrm{~A} 10, \mathrm{~A} 12, \mathrm{~A} 13, \\
\mathrm{~A} 20, \mathrm{~A} 28\end{array}$ & 6 \\
\hline A27 & $\mathrm{A} 14, \mathrm{~A} 26, \mathrm{~A} 28, \mathrm{~A} 32$ & 4 \\
\hline
\end{tabular}

A grubu kamu hastanelerin girdi değişkenli BCC toplam etkinliği CRS temel alınarak yapılan analiz sonucunda A1 kodlu hastanenin A7, A10, A14, A31 ve A32 kodlu hastaneleri referans alması gerektiği ve ayrica A1 hastanesinin etkin olabilmesi için 400 olan yatak sayısını 55 adet azaltmas1, 106 olan uzman hekim sayısinı ortalama 3 azaltması, 19 adet pratisyen hekim sayısını yaklaşık 1 azaltması, 280 adet hemşire sayısını 7 azaltmas1, 60 adet ebe sayısinı yaklaşık 2 adet azaltması ve 19086 adet yatan hasta sayısını 63 artırması, 515 A grubu ameliyat sayısını 133 artırmas1, 3050 adet B grubu ameliyat sayisin 1 ise 125 adet artırması ve diğer girdi ve çıktıları sabit bırakması gerektiği anlaşılmıştır.

$\mathrm{B}, \mathrm{C}, \mathrm{D}$ ve $\mathrm{E}$ grubu hastanelerin etkinlik bulgularının detaylı görmek için bahsedilen ilgili tez incelenebilir. Özet sonuçlar bir sonraki başlıkta verilmektedir.

\section{SONUÇ VE ÖNERILLER}

Sağlık hizmeti sunumunun başında hastaneler bulunmaktadir. Hastaneler incelendiğinde yüksek yatırımlara sahip, bütçeleri olan ve işlem maliyeti yüksek sağlık işletmeleri olduğu görülmektedir. $\mathrm{Bu}$ işletmelerin kaynaklarının etkin kullanılması kamu yararı ve toplumsal fayda açısından son derece önemlidir.

Bu çalışmada Karadeniz Bölgesi'nde yer alan 124 adet kamuya ait hastane, kendi aralarında rollerine göre ayrılmıştır. $\mathrm{Bu}$ hastanelerin 33'ü A rolünde, 19'u B rolünde, 25 'i C rolünde, 26's1 D rolünde ve 21'i $\mathrm{E}$ rolündedir. Yöntem olarak 2018 y1lı verileri kapsamında VZA yönteminden kullanılmıştır. Hastane verileri Sağlık Bakanlığı'nın TSİM sisteminden temin edilmiştir.

Çalışmada, hastane etkinlikleri "girdi yönlü BCC modeli” kullanılarak hesaplanmıştır. $\mathrm{Bu}$ hesaplama neticesinde etkin olan ve olmayan hastaneler belirlenmiştir. Etkin hale gelebilmesi için referans alınması gereken hastaneler gözlemlenmiştir. Ayrıca hastanelerin azaltması veya artırması gereken girdi ve çıktı miktarı hesaplanmıştır.
Hastaneler incelendiğinde 33 adet A grubu hastanenin 12 tanesi branş hastanesi, 21 adeti aynı rolde hastane olduğundan ayrı ayrı etkinlikleri ölçülmüştür. 12 adet branş hastanesinin 2 tanesi etkin olmadı $\breve{g} 1,10$ tanesinin ise etkin olduğu görülmüştür. 21 adet A rolündeki hastanelerin ise 5 tanesinin etkin olmadığı 16 tanesinin etkin olduğu sonucuna ulaşılmıştır. Genel itibariyle A grubu hastanelerde etkinlik göze çarpmaktadır.

19 adet B rolündeki hastanenin etkinlik hesaplanması yapıldığında 7 tanesinin etkin olmadığı, 12 tanesinin ise etkin olduğu görülmüştür. Yine analiz sonuçlarına göre 25 adet $\mathrm{C}$ rolündeki hastanenin 14 tanesi etkin olmadığı, 11 tanesinin ise etkin olduğu anlaşılmaktadır. 26 adet $\mathrm{D}$ rolündeki hastanenin 16 tanesinin etkin olmadığı, 10 tanesinin ise etkin olduğu anlaşılmaktadır. Son olarak 21 adet E rolündeki hastanenin ise 8 tanesinin etkin olmadı $\breve{g} 1,13$ tanesinin ise etkin olduğu görülmüştür.

Rollerine göre hastanelerin etkinlikleri incelendiğinde aralarında farklılaşma görülmektedir. En etkin hastane rolü A hastanesi iken, en az etkin hastaneler D rolü 
hastanelerdir. Yine $\mathrm{C}$ rolündeki hastanelerin etkinliğinin düşük olduğu gözlemlenmektedir. En düşük etkinliğe sahip $\mathrm{C}, \mathrm{D}$ ve $\mathrm{E}$ rollerindeki hastaneler ilçe merkezlerinde faaliyet göstermektedirler. Hastaneler arasında ortaya çıkan etkinlik farklılaşmasının nedenlerinin ortaya koyulması ve çözüme kavuşturulması il ve bölge bazında sağlık etkinliğinin artırılması açısından önemlidir.

Analizini yapmış olduğumuz hastanelerin etkinlik ortalamasında azalışın temelinde, plansız yapılan personel hareketleri ve plansız azaltılan yatak kapasiteleri olarak görülmektedir. $\mathrm{Bu}$ temel nedenler hastanelerin yönetimsel olarak istenilen düzeyde yönetilmediği anlamını taşımaktadır. Etkin olmayan hastanelerin etkin duruma gelmesi için personel planlamasının dengeli bir şekilde yapılması, hastanelerin kapasite kullanım oranlarının yükseltmesi, teknolojik yatırımların artırılarak ameliyat sayılarının ve tedavisi yapılan hasta sayılarının artırılması gerekmektedir.

\section{KAYNAKLAR}

1. Sağlık Bakanlığı. (2011). Sağlığın Teşviki ve Geliştirme Sözlüğü. Ankara: Anıl Matbaacılık.

2. Orhaner, E. (2006). "Türkiye'de Sağlık Hizmetleri Finansmanı ve Genel Sağlık Sigortası". Gazi Üniversitesi Ticaret ve Turizm Eğitim Fakültesi Dergisi, (1), 1-22.

3. Carrin, G, Buse, K, Heggenhougen, K. ve Quah, S.R. (2010) Health Systems Policy, Finance, and Organization. Switzerland: Academic Press.

4. Basan, N.M. ve Bilir, N. (2016). "Koruyucu Sağlık Hizmetlerinde Önleme Çelişkisi ve Nedenleri”. TAF Preventive Medicine Bulletin, 15 (1), 44-51.

5. Ateş, M. (2013). Sağlık Sistemleri Yönetimi. İstanbul: Beta Basım Yayınevi.

6. Gençoğlu, P. (2018). "Türkiye'de İllerin Gelișmişlik Düzeyi Dikkate Alınarak Sağlık Hizmetlerinin Kümeleme Analizi Aracılığıyla Değerlendirilmesi”. Erciyes Üniversitesi İktisadi ve İdari Bilimler Fakültesi Dergisi, (52), 301-324

7. Ağırbaş, İ. (2006). Hastane Yönetimi ve Organizasyonu. Ankara: Siyasal Kitabevi.

8. Seçim, H. (1991). Hastane Yönetimi ve Organizasyonu: Türkiye'de Hastanelerin Organizasyonu İçin Bir Model Önerisi. İstanbul: İșletme Fakültesi Yayınları.

9. Kavuncubaşı, Ş. (2000). Hastane ve Sağlık Kurumları Yönetimi. Ankara: Siyasal Kitabevi.

10. Tengilimoğlu, D, Akbolat M. ve Ișık, O. (2009). Sağlık İşletmeleri Yönetimi. Ankara: Nobel Basım Evi.

11. Danacı, B. (2010). Üniversite ve Özel Hastanelerin Yatakl Birimlerinde Görev Yapan Hemşirelerin İş Tatminlerinin Karşılaştırılması. Yüksek Lisans Tezi, Dumlupınar Üniversitesi Sosyal Bilimler Enstitüsü, Kütahya.

12. Tengilimoğlu D, Işık O. ve Akbolat, M. (2012). Sağlık İşletmeleri Yönetimi. Ankara: Nobel Yayınları.

13. Arslan, S. (2008). Faaliyet Tabanlı Maliyetleme ve Bir Hastane İşletmesi Üzerine Uygulama. Yüksek Lisans Tezi, Niğde Üniversitesi Sosyal Bilimler Enstitüsü, Niğde.

14. Kavuncubașı, S. (2007). Sağlık Kurumları Yönetimi. Eskişehir: Anadolu Üniversitesi Yayınları.

15. Kavak, D.G. (2018). "Türkiye Sağlık Hizmetleri Kalite ve Akreditasyon Enstitüsü Sağlıkta Akreditasyon Standartları". Sağlıkta Kalite ve Akreditasyon Dergisi, 1 (1), 14-20.
16. Turner, L.G. (2011). "Quality in Health Care and Globalization of Health Services: Accreditation and Regulatory Oversight of Medical Tourism Companies". International Journal for Quality in Health Care, 23 (1), 1-7.

17. Kerman, U, Altan, Y, Aktel, M. ve Eke, E. (2012). "Sağlık Hizmetlerinde Kamu Özel Ortaklığı Uygulaması”. Süleyman Demirel Üniversitesi İktisadi ve İdari Bilimler Fakültesi Dergisi, 17 (3), 1-23.

18. Şahin, İ. (2008). "Sağlık Bakanlığı Genel Hastaneleri ve Sağlık Bakanlığına Devredilen SSK Genel Hastanelerinin Teknik Verimliliklerinin Karșılaștırmalı Analizi”. Hacettepe Üniversitesi Hacettepe Sağlık İdaresi Dergisi, 11 (1), 1-48.

19. Öztürk, Y.E. (2009). Türk Sağlık Sektörü İçerisindeki Üniversite Hastanelerinin Etkinliğinin Artırılmasında Dıs Kaynak Kullanımı Uygulamasının Etkisi Üzerine Veri Zarflama Analizine Dayalı Bir Araștırma. Doktora Tezi, Selçuk Üniversitesi Sosyal Bilimler Enstitüsü, Konya.

20. Aytekin, S. (2011). "Yatak İşgal Oranı Düşük Olan Sağlık Bakanlığı Hastanelerinin Performans Ölçümü: Bir Veri Zarflama Analizi Uygulaması”. Uludağ Üniversitesi İktisadi İdari Bilimler Fakültesi Dergisi, (1), 113-138.

21. Bal, V. ve Bilge, H. (2013). "Eğitim ve Araştırma Hastanelerinde Veri Zarflama Analizi ile Etkinlik Ölçümü”. Manas Sosyal Araștırma Dergisi. 2 (2), 1-14.

22. Demiray, E. ve Güneş, İ. (2014). “Türkiye'deki İllerin Sağlık Etkinliklerinin Analizi”. Ekonomi Bilimleri Dergisi, 6 (2), 1 19.

23. Öksüzkaya, M. (2017). "Sağlık Sektöründe Bölgeler Arası Etkinliğin İncelenmesi”. Gazi Üniversitesi Sosyal Bilimler Dergisi, 4 (10), 218-300.

24. Şenol, O. ve Gençtürk, M. (2017). "Veri Zarflama Analiziyle Kamu Hastaneleri Birliklerinde Verimlilik Analizi". Süleyman Demirel Üniversitesi Sosyal Bilimler Enstitüsü Dergisi, 29 (4), 265-286.

25. Bağc1, H. (2018). Kamu Hastaneleri Hizmet Sunum Performansının Veri Zarflama Analizi ve Malmquist İndeksi Yöntemleriyle Değerlendirilmesi. Doktora Tezi, Gazi Üniversitesi Sosyal Bilimler Enstitüsü, Ankara.

26. Çınaroğlu, S. (2018). "Eğitim ve Araştırma Hastanesi Olan ve Olmayan Hastanelerin Teknik Verimliliklerini Veri Zarflama Analizi ile Karşılaştırılması". Hacettepe Üniversitesi Sağlık İdaresi Dergisi, 21 (2), 179-198.

27. Esen, H. ve Yiğit, V. (2019). "Kamu Hastanelerinde Verimlilik Ölçümü: Akdeniz Bölgesi Örneği”. Avrasya Sosyal ve Ekonomi Araştırmaları Dergisi, 6 (7), 134-144. 
28. Taşkaya S. (2020). "Türkiye'deki Eğitim ve Araștırma Hastanelerinin Verimliliğin Pabon Lasso ve Veri Zarflama Analizi ile Belirlenmesi”. Hacettepe Üniversitesi Sağlık İdaresi Dergisi, 23 (2), 247-260.

29. Prokopenko, J. (1992). Verimlilik Yönetimi Uygulamalı El Kitabı. (Çev: O. Baykal, N. Atalay ve E. Fidan). Ankara: Milli Prodüktive Yayınları.

30. Güran, M.C. (2005). Kamu Hizmetlerinde Performans Ölçümü: Türkiye'deki Kamu Üniversiteleri İçin Bir Performans Ölçümü Uygulaması. Ankara: Hacettepe Üniversitesi Yayınları.

31. Banta, D. (2003). "The Development of Health Technology Assessment". Health Policy, 63 (2), 121-132.

32. Pelone, F, Kringos, D.S, Romaniello, A, Archibugi, M, Salsiri, C. ve Ricciardi, W. (2015). "Primary Care Efficiency Measurement Using Data Envelopment Analysis: A Systematic Review". Journal of Medical Systems, 39 (1), 1 14.

33. Farrell, M.J. (1957). "The Measurement of Productive Efficiency". Journal of the Royal Statistical Society, 120 (3), 253-281

34. Charnes, A, Cooper, W.W. ve Rhodes, E. (1978). "Measuring The Efficiency of Decision Making Units". European Journal of Operational Research, 2 (6), 429-444.

35. Özkan, M. ve Özcan, A. (2018). "Veri Zarflama Analizi ile Seçilmiş Çevresel Göstergeler Üzerinden Bir Değerlendirme: OECD Performans İncelemesi”. Yönetim Bilimleri Dergisi, 16 (32), 485-508.

36. Atalan, A. (2018). "Türkiye Sağlık Ekonomisi İçin İstatistiksel Cok Amaçlı Optimizasyon Modelinin Uygulanması". İşletme Ekonomi ve Yönetim Araştırmaları Dergisi, 1 (1), 34-51.

37. Banker, R.D, Charnes, A. ve Cooper, W.W. (1984). "Some Models for Estimating Technical and Scale Inefficiencies in Data Envelopment Analysis". Management Science, 30 (9), 1078-1092.

38. Liu, C. (2007). "DEA Study to Evaluate the Relative Efficiency and Investigate the Reorganization of the Credit Department of Farmers Associations in Taiwan". Applied Economics, 39 (20), 2663-2671.

39. Aydemir, Z.C. (2002). Bölgesel Rekabet Edebilirlik Kapsamında İllerin Kaynak Kullanım Göreceli Verimlilikleri: Veri Zarflama Analizi Uygulaması. Uzmanlık Tezi, Devlet Planlama Teșkilatı Yayınları, Ankara.

40. Sarı, Z. (2015). Veri Zarflama Analizi ve Bir Uygulama Yüksek Lisans Tezi, Hacettepe Üniversitesi Fen Bilimler Enstitüsü, Ankara. 